\title{
Identifying difficulties in teaching foreign language speaking in the online environment
}

\author{
Tatiana Valeryevna Potemkina*, Lilia Vladimirovna Bondareva, Ekaterina Nikolayevna \\ Shchaveleva, Dana Serikovna Saulembekova, and Thi Hue Le \\ National University of Science and Technology MISIS, Department of Modern Languages and \\ Communication, Moscow, Russia
}

\begin{abstract}
The digital transformation of education has been causing dramatic changes in the organization and curriculum of the educational process. The problem of mastering foreign language speaking skills by university students in distance learning format has been attracting growing attention in academic circles worldwide. In addition to the technical difficulties faced by the stakeholders of the online learning process, there has been an increasing focus on other related factors, including psychological barriers and emerging interaction patterns in both student-student communication and teacher-student communication. In this paper, the authors will identify the difficulties faced by the students who learn speaking skills online. A survey was conducted among students of technical specialties of the NUST MISIS University. The survey involved 16 students who were studying English online. The conducted experiment revealed several types of psychological difficulties that arise while learning to speak online. The results of the study will help improve the quality of academic programs in terms of identifying the existing gaps in designing and managing speaking classes online.

Keywords: distance learning, online learning, foreign language, speaking, dialogue, university teaching, non-linguistic specialties, and difficulties
\end{abstract}

\section{Introduction}

Until the year 2020, the distance learning format in Russia had not been particularly popular among educational institutions and was mainly considered as a complementary way to the main formats of teaching. According to the data from the Ministry of Science and Higher Education of the Russian Federation, in 2017 no more than 13\% of students were involved in distance learning across the country [1].

The global experiment to introduce distance education as a result of the pandemic has made this form of learning practically mainstream and required the mobilization of all participants in the educational process to build a sustainable learning environment: from administrators of training programs to teachers and students [2]. University staff faced the

${ }^{*}$ Corresponding author: potemkinatv@mail.ru 
need to transfer previously full-time offline courses to online-only [3]. That has caused the need to find effective ways to organize training.

Teaching a foreign language to future engineers is a priority in their training, which is closely related to the increasing importance of the humanitarian component in their professional activities [4-7]. "Any employer in the field of engineering wants the new employees to have a skillset including teamwork, communication, or time management skills that have been ignored in the past [8]. Engineers are tasked with being "effective communicators" [9] since they need to convey complex ideas and technical project plans, participate in discussions when developing engineering solutions [10]. Moreover, "engineering practice takes place in an intensely oral culture" [11], and the ability to publicly support the results of their research is of growing significance [8].

The pedagogical and scientific community has formed an opinion that distance learning can hardly ever become an indisputable equivalent to the traditional format of learning at a university since the interaction between a teacher and students via digital technologies in the learning process imposes certain restrictions on the students' mastering of the learning content $[12,13]$.

Searching for ways to design a learning environment that would take into account those subtle features has been of particular importance for educators involved in training future specialists in oral English [14].

The difficulties in the formation of dialogical speech skills arise from their situational nature, the necessity to select speech tools for a given context, organize the speech content, engage in specific forms of interaction when resolving the emerging communication difficulties.

To develop speech skills, there have been employed various tools and strategies which focus on several language skills or one skill in particular. They include role-playing, games, topical discussions, debates, question-and-answer sessions, etc.

The experience of building online classes for the development of dialogical speech has shown that there are barriers that hinder productive learning [15].

The issues related to modeling approaches in the development of effective scenarios for online lessons, which would take into account the difficulties encountered by students in mastering a foreign language dialogical speech, remain to be insufficiently studied today.

The search for effective learning methods is hardly possible unless we carefully analyze the obstacles that students face in online learning when mastering oral English skills.

The purpose of the study is to identify the difficulties faced by students of technical specialties, mastering foreign language speaking skills in the context of professional communication in distance learning.

\section{Methods}

The application of the literature review method is justified by the task of identifying a problem that requires a more profound reflection.

As a part of the study, an analysis of the university context of teaching English to students of technical specialties was carried out.

The main method for collecting empirical data was an online survey. The content of the survey was devised for and aimed at university engineering students.

The survey involved 16 students from the technical colleges training future engineers at the NUST MISIS University.

The following questions were included in the questionnaire:

1. How do you rate your level of English proficiency? 
2. How do you feel when speaking English?

3. Do you have any experience in discussing your profession in English during an online class? (experience of interacting with someone: interviews, discussion, conversation, etc.)

4. In your opinion, how effective is learning English through interaction?

5. How often do you participate in English-speaking activities?

6. What are your favorite types of English-speaking activities?

\section{$3 \quad$ Results}

An analysis of the learning conditions at the NUST MISIS suggests that the formation of English groups of students of technical specialties is based on the language proficiency level. An online placement test was developed on the LMS platform provided by the educational partner of the Cambridge University Press, which evaluates the level of vocabulary and grammar proficiency as well as listening and writing skills of the tested students. Although oral testing has not been carried out, placement errors in group enrollment are within $5-7 \%$ of all test results.

The learning methodology applied by the Department of Modern Languages and Communication at NUST MISIS is based on the communicative methods in teaching foreign languages. Since 2010, NUST MISIS has been implementing intensive language training for technical students and blended learning using online technologies, specially developed in partnership with Cambridge University Press. The program also integrates elements of project-based learning to develop communication skills, critical thinking, collaboration, and creative skills,

The university facilities allow for the application of a variety of pedagogical technologies in mixed, hybrid, and mobile learning when designing educational programs in a distance format.

Survey results of students of technical specialties.

Students from different faculties and groups participated in the survey.

Below are the results of the survey.

For the first question, $18.8 \%$ of the participants reported that the level of English proficiency was A1, 6.1\% indicated the level as A2, 43.8\% self-identified at level B 1, 25\% $-\mathrm{B} 2,6.3 \%-\mathrm{C} 1$.

How do you rate your level of English proficiency?

16 responses

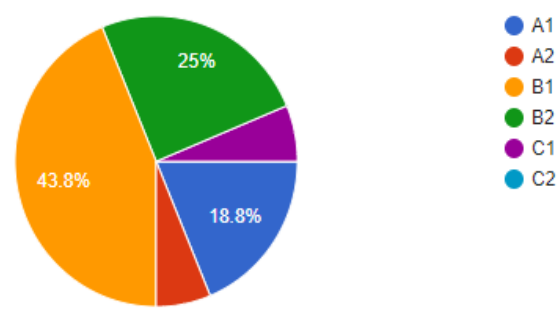

Fig. 1. Levels of English proficiency in survey participants. 
The next question was aimed at identifying students' skills in English speaking.

The diagram shows the distribution of students concerning self-assessment of English speaking skills. $12.5 \%$ of participants reported that they felt very comfortable when speaking in English, 31.3\% - more or less comfortable, $12.5 \%$ - not very uncomfortable, and the remaining $6.2 \%$ of participants felt very uncomfortable.
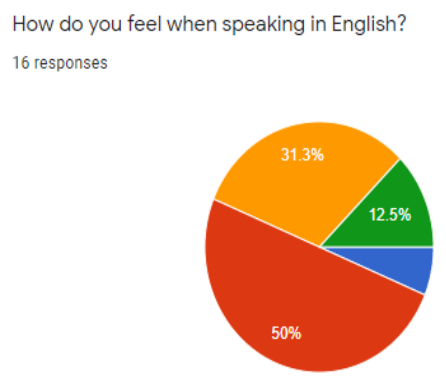

Very uncomfortable

A little uncomfortable

Comfortable

Very comfortable

Fig. 2. Participants' self-assessment of English speaking skills.

The next question was aimed at learning about the students' experience of participating in classroom discussions related to professional topics in English.

The diagram shows the results of the survey. $31.3 \%$ of the participants reported that they had no experience in discussing any issues related to their future profession in English, $18.8 \%$ had little experience, $31.3 \%$ said they had some experience, and $12.5 \%$ answered that they had a fairly comprehensive communication experience.
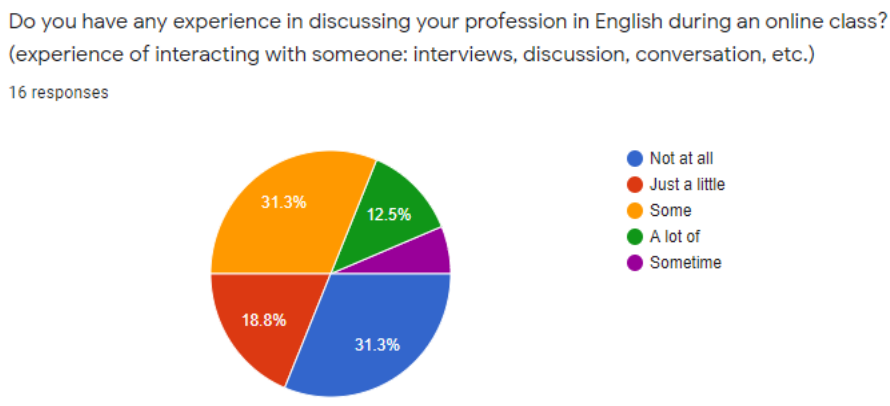

Fig. 3. Students' experience of participating in classroom discussions related to professional topics in English.

The survey revealed the students' preferences in learning methods, which, in their opinion, are efficient and based on interaction during the learning process.

The diagram shows the results of the survey. $50 \%$ of the participants reported that learning through interaction is efficient, $31.3 \%$ - indicate that interaction is extremely efficient, $12.5 \%$ question the effectiveness of this method of learning to speak, and $6.3 \%$ do not see the benefits of this method. 
In your opinion, how effective is learning English through interaction?

16 responses

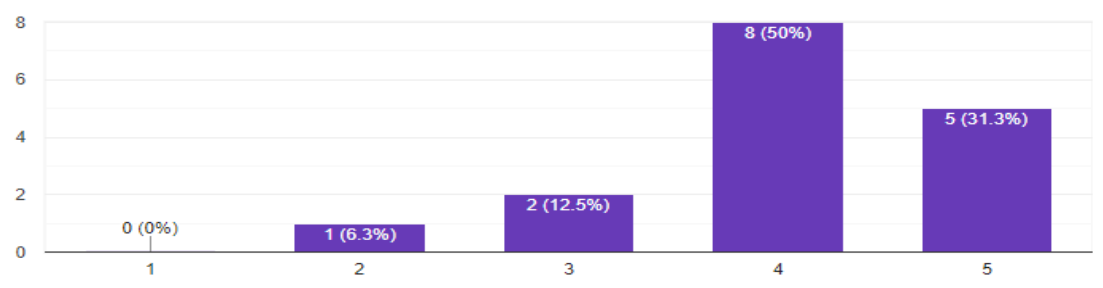

Fig. 4. Student Assessment of Learning Efficiency Through Interaction.

The answer to this question allows us to appreciate the demand for foreign-language professional communication by future engineers.

The diagram shows the results of the survey. $25 \%$ of participants reported that they often participated in English-language events, 50\% - sometimes, $18.8 \%$ - rarely, and the remaining $6.2 \%$ of participants reported that they never participated in English-language events outside of the classroom.

How often do you participate in English Speaking activities?
16 responses

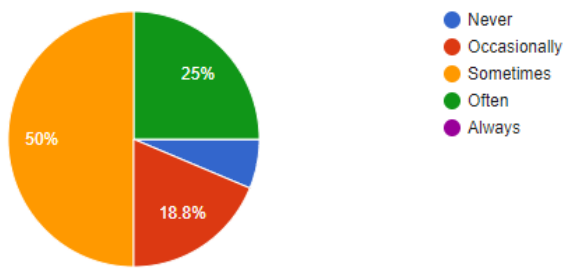

Fig. 5. Frequency of students' participation in English-speaking events.

The questionnaire included a question aimed at identifying students' preferences in pedagogical methods applied for the development of oral dialogical speech skills.

The diagram shows the results of the survey. $80 \%$ of the participants reported that they enjoyed conversational activities, $40 \%$ preferred discussions, $20 \%$ - role-plays, $13.3 \%$ voted for interviews, and $13.3 \%$ preferred debates.

What are your favourite types of English Speaking activities?

15 responses

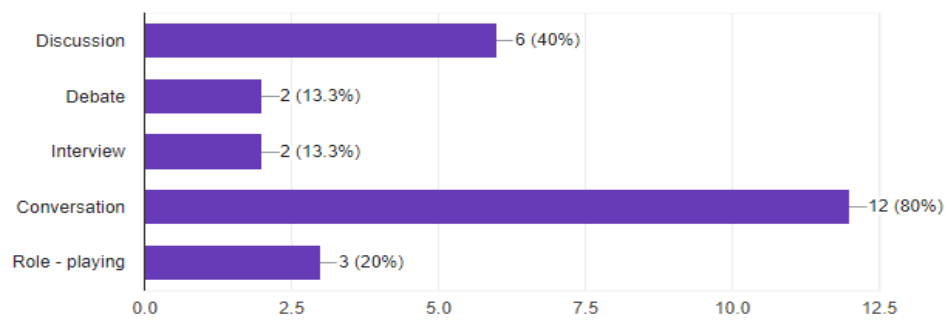


Fig. 6. Preferences in pedagogical methods.

Based on the data obtained, we can conclude that most of the participants face difficulties in a dialogical speech in a foreign language in the context of distance education.

Selective interviews with survey participants showed that students had a degree of exposure to the professional communication context and participated in various online events (seminars, conferences, and master classes). That was mentioned by about $25 \%$ of the respondents. Some of the problems they experienced with online English classes included a lack of willingness to interact ("I can't always take the initiative", "when those who speak English better than I speak, I'm afraid to look funny", "if in a discussion three or more students participate, I prefer to be silent"), a teacher's lack of expertise in engaging students in the speech activity during an online lesson ("sometimes I don't get my turn", "I need someone to ask me to speak out").

\section{Discussion}

Awareness of the benefits of digitalization, which offers abundant opportunities in the area of teaching foreign languages, one should not overlook a critical assessment of the learning process in the context of digitalization.

Overcoming technical obstacles does not solely guarantee effective learning.

Taking into account the increasing role of verbal professional communication of engineering specialists when performing work online, the development of such competence is of fundamental importance. This new reality feature is indicated by many researchers [16]. In the scientific community, issues of identity/differences in the organization of the distance learning process and the corresponding interaction patterns in the classroom are being actively discussed [12]. It has been argued that oral communication skills (listening and speaking) in online learning are formed with the help of active interpersonal influence similar to traditional offline learning [16]. Also, it is argued to be possible to master certain oral speaking skills, i.e. pronunciation, conversation, communication with peers, and interaction with a teacher [2]. However, the question remains why even the most adaptive technological platforms (Zoom, Skype, Microsoft Teams) do not completely "transfer" well-proven pedagogical learning technologies to the online environment. A certain "adaptation" of these teaching methods to new conditions is required.

The study confirms the assumptions made earlier about the existence of certain obstacles in building the interaction between a teacher and students and/or the one within student groups in the process of teaching oral dialogical speech in a distance format. What has been added to those assumptions is the above-mentioned opinions of the students about what methods of organizing distance learning sessions would make the learning process more effective. For example, conversations are more popular compared to role-plays, debates, and discussions, and the need for stimulating speech interaction in the classroom cannot be overrated.

The low level of involvement of future specialists in professional events held remotely may be accounted for not only due to a low level of English proficiency (about $25 \%$ of respondents) but also due to the lack of skills required for participating in such events (31.3\% of survey participants reported a lack of experience in discussing their profession in English, 18.8\% have little experience).

The survey showed that a significant number of students consider learning in the online environment as insufficiently productive for developing their speaking skills: only half said 
that the distance learning format of learning English speech was productive. For the remaining half of all the respondents that format was novel and less efficient.

\section{Conclusion}

The study showed that, in addition to a perceived lack of experience in discussing professional topics in English online, engineering students focus on issues that are directly related to changes in the classroom environment. These conditions do not allow for employing well-tested methods of interaction between the teacher and students and/or the interaction between students. Such issues include a "lack of involvement" in a conversation during an oral speech interaction with three or more participants as well as a low level of independence in speech interactions during classroom activities without the teacher's active participation and guidance.

\section{References}

1. Ministry of Science and Higher Education of the Russian Federation, Information about the organizations carrying out educational programs of higher education bachelor's programs, specialist programs, master's programs (2017) https://minobrnauki.gov.ru/action/stat/highed/

2. D. Bailey, N. Almusharraf, R. Hatcher, Edu Inf Tech, 26(3), 2563-2583 (2021). https://doi.org/10.1007/s10639-020-10369-z

3. C. Rapanta, et al., Postdig Sci Edu, 2(3), 923-945 (2020). https://doi.org/10.1007/s42438-020-00155-y

4. S.K. Howard, M. Khosronejad, R.A. Calvo, Europ J Eng Edu, 42(6), 875-889 (2017). https://doi.org/10.1080/03043797.2016.1228612

5. C.S. Sankar, Int J Project Manag Product Assess, 9(2), 1-16 (2021). https://doi.org/10.4018 / IJPMPA.20210701.oa

6. H.J. Passow, C.H. Passow, J Eng Edu, 106(3), 475-526 (2017). https://doi.org/10.1002/jee.20171

7. J.D. Ford, L.A. Riley, J Eng Edu, 92(4), 325-328 (2003). https://doi.org/10.1002/j.2168-9830.2003.tb00776.x

8. M. Bucur, A. Ban, Procedia Manuf, 32, 348-355 (2019). https://doi.org/10.1016/j.promfg.2019.02.224

9. J.D. Lang, S. Cruse, F.D. McVey, J. McMasters, J Eng Edu, 88(1), 43-51 (1999). https://doi.org/10.1002/j.2168-9830.1999.tb00410.x

10. M.J. Riemer, Glob J Eng Edu, 6(1), 91-100 (2002)

11. A.L. Darling, D.P. Dannels, Comm Edu, 52(1), 1-16 (2003). https://doi.org/10.1080/03634520302457

12. I. Doyumgaç, A. Tanhan, M.S. Kiymaz, Int J Higher Edu, 10(1), 166-190 (2021). https://doi.org/10.5430/ijhe.v10n1p166

13. C.J. Edwards-Groves, R.L. Hoare, Australian J Teacher Edu, 37(8), 82-100 (2012). https://doi.org/10.14221/ajte.2012v37n8.8

14. M.J. Riemer, Glob J Eng Edu, 11(1), 89-100 (2007)

15. M. Sapia, G. Heller, D. Dawson, N. Carmack, Res Pract Assess, 15(1), 1-16 (2020). 
16. R.D. Costigan, K.E. Brink, J Manag Edu, 44(2), 129-164 (2020).

https://doi.org/10.1177/1052562919890895 